\title{
Proposal for Grease Replacement System for Traction Motor Bearings
}

\author{
Sumiko HIBINO \\ Senior Researcher, \\ Kazuo NAKAMURA \\ Senior Researcher,
}

Tetsuya HOSOYA

Senior Researcher,

Lubricating Materials Laboratory, Material Technology Division

The "interim greasing" method is one of the general solutions for extending the lifespan of grease, and has been adopted for some types of induction traction motors. However, the conventional way of planning interim greasing requires leaving some empty space to refill additional grease due to the limited room. Accordingly, trouble sometimes occurs due to insufficient lubrication during the initial stages of the motor operation. To solve this problem, a new device was designed which enables grease refilling without providing an empty space by replacing the deteriorated grease with the less deteriorated one inside the grease pocket.

Keywords: traction, interim grease supply, tribology, rolling bearing, lubricating life

\section{Introduction}

In railway vehicle maintenance, inspection and repairs around bogies are extremely important. Several lubricants are used for devices and equipment to keep them in good condition, the lifespan of lubricants is shorter than the devices on which they used on the bogies. Consequently lubricants need periodic replacement. Replacing the lubricant used on traction motor bearings is the one of the most onerous operations in terms of time and cost since it involves motor disassembly and removal of the rotor. As a result there is great demand to reduce the frequency of this intervention.

\section{The service life of grease}

One method for extending the service life of grease is to improve the performance of the grease itself. In recent years, grease and bearing manufacturers have developed grease containing synthetic oil as a base oil; however, this does not solve the fundamental problems affecting railway vehicles.

Grease filling devices have also been redesigned. The generally accepted view is that the more grease is packed in or near the bearing, the longer the service life of grease becomes. Since filling volumes are already fixed according to the inner space between bearings (in consideration of space required to allow for the rotating motion of the rolling elements and the cage), introducing larger volumes of grease is only possible by installing grease pockets (GPs) on both outer sides of the bearing. Figure 1 shows the typical profiles of end-plate GPs. After comparison of the profiles a proposal was made to fit two outer GPs, connected to a ring shaped GP (types A and B, Fig. 1). This maximizes the contact area between the ring and outer GPs, in accordance with the design guideline of ensuring high grease-oil supply capacity [1].

The method for replenishing grease to the assembled state is called "interim greasing" and adopted for some types of induction traction motors is another solution for extending the lifetime of the grease. However, so far there is no confirmed procedure using this method to obtain the

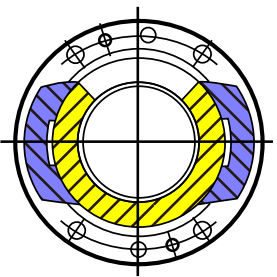

Type A

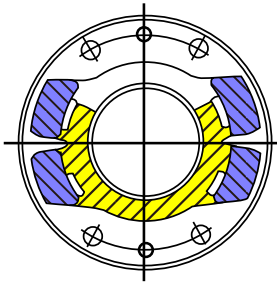

Type B

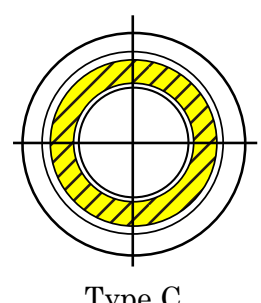

Type $\mathrm{C}$
Fig. 1 Hollow shaped variations in traction motor end caps

best performance in intermediate refilling, and thus grease supply ports or "grease nipples" are fitted for emergency use but in many cases are largely left unused. Wherein this report collected and ordered the problems found in conventional interim grease supply, and designed a new type of equipment which makes it possible to replace the used grease with the less deteriorated grease inside the grease pocket of the outer-cover. Timing appears to be a crucial element influencing the effectiveness of interim grease supplying. As such this paper also investigates the most effective timing for grease supply and proposes a new method combining the optimal mechanical structure with optimal timing of additional grease supply.

\section{The conventional method in refilling and its prob- lems}

"Interim greasing" [2] is a technique used for improving lubrication without disassembly while extending the service life of the lubrication by feeding new grease at appropriate times directly into the lubricating device using grease nipples on the outer shell.

Replacing deteriorated grease in the bearings with fresh grease renews the oil film on the phreatic surface. Although this type of operation does not achieve the same level of renewal as disassembly and rinsing out, it has been recognized as an effective interim means to extend the service life of the grease without disassembly during the motor's operation.

There may on occasion be marginal space around bear- 


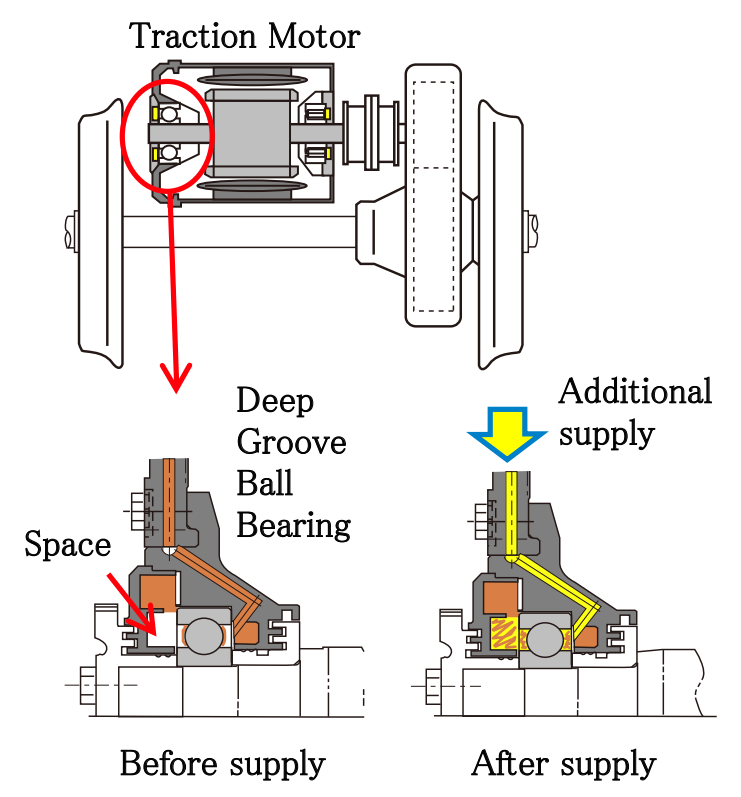

Fig. 2 Sectional view of an induction motor and conventional interim grease supply

ings into which grease may be introduced, however redundant grease is pushed out when the shaft rotates, eliminating any concern about over-greasing. On the other hand, there is limited space to hold grease around the bearings in traction motors; therefore, excess grease can cause the temperature to rise through churning leading to bearing failure. Accordingly it is necessary to accurately control the volume of grease employed.

Supplying grease by the conventional way involves freeing a space (Fig. 2) equivalent to the volume of refilling grease, in order to avoid over greasing. However, the internal condition of the bearing cannot be verified without disassembly, making it difficult to supply the exact amount of grease required.

In addition, the internal space around the bearings has to be divided between initial filling and interim refilling. This means that the initial amount of grease must be reduced by the same volume as supplied during interim greasing, which may cause problems due to insufficient lubrication in the initial stages of motor operation [3].

To solve this problem and improve the effectiveness of interim greasing, a new device was designed, which enables greasing without prior partial emptying of the grease pocket. This is done by replacing the used grease with the less deteriorated grease inside the grease pocket. Such an approach also makes it possible to achieve an accurate grease refilling volume without having to observe inside.

\section{A New interim greasing supply mechanism}

\subsection{Permutation of new grease}

The drawback of the conventional method described above is that unfilled gaps remain very close to the bearings, which may result in poor lubrication, initially.

In order to preserve correct lubrication of the bearings from assembly and throughout its service life, a sufficient

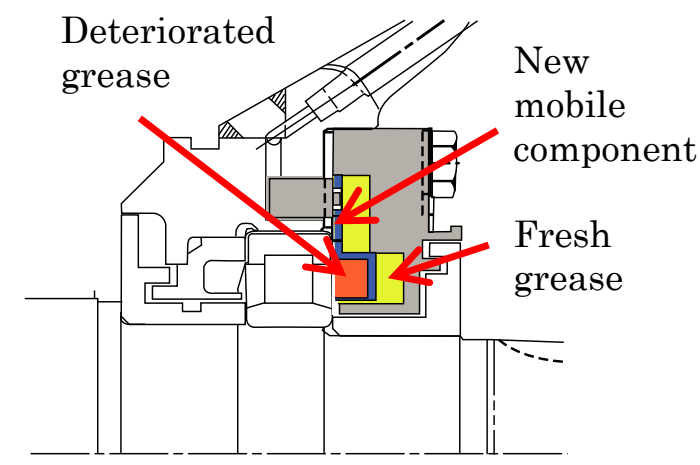

(a) Before supply

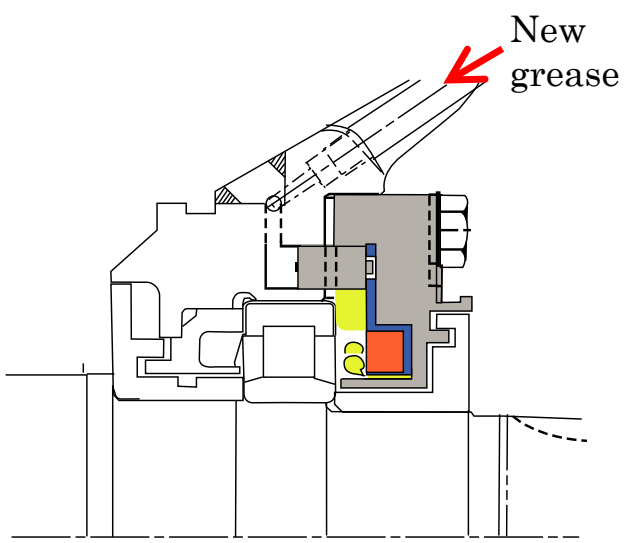

(b) After supply

Fig. 3 New interim greasing system

supply of grease must be applied all around the bearings. If the grease does not penetrate in and around the bearings and fails to be in direct contact with them, lubrication is less effective. As a result, it is important to determine exactly how the space in the end-cap grease pocket, which is crucially positioned facing the bearings, will be used.

Consequently in the new interim greasing system, the grease pocket is pre-filled to capacity (full-pack). At the time of interim greasing, the newly introduced component makes it possible to flush out the old grease and supply the fresh grease into and around the bearings. The developed system is shown in Fig.3.

A new component was designed to realize the mechanism for replacing the grease in the grease pocket. The new mobile component divides the ring shaped grease pocket vertically into two compartments (shown in blue in Fig 3). During inspections requiring disassembly, grease is prepacked into the lower compartment underneath the mobile plate component (into the bottom of the GP). During subsequent interim greasing, by pushing the mobile plate 'away' from the bearings pressure is exerted on the grease in the lower pocket, which has the effect of squeezing it towards the bearings. Given that this means the exact amount of grease can be supplied, the result is a more stable lubrication effect.

This report investigates mineral-base lithium complex grease, widely applied for traction bearing lubrication. Table 1 shows the test grease properties.

Figure 4 shows the surface of the grease pocket facing the bearing first in deteriorated condition before (left) 
Table 1 Grease Properties

\begin{tabular}{|l|l|}
\hline Grease & Lithium Complex Grease \\
\hline Oil Type & M ineral Oil \\
\hline $\begin{array}{l}\text { Oil Viscosity, } \\
\mathrm{mm}^{2} / \mathrm{s}, 100^{\circ} \mathrm{C}\end{array}$ & 11.5 \\
\hline $\begin{array}{l}\text { Worked Penetration } \\
\text { Dropping Point, }{ }^{\circ} \mathrm{C}\end{array}$ & 280 \\
\hline $\begin{array}{l}\text { Oil Separation, } \\
\text { mass } \%, 100^{\circ} \mathrm{C} \times 24 \mathrm{~h}\end{array}$ & 0 ver 260 \\
\hline
\end{tabular}

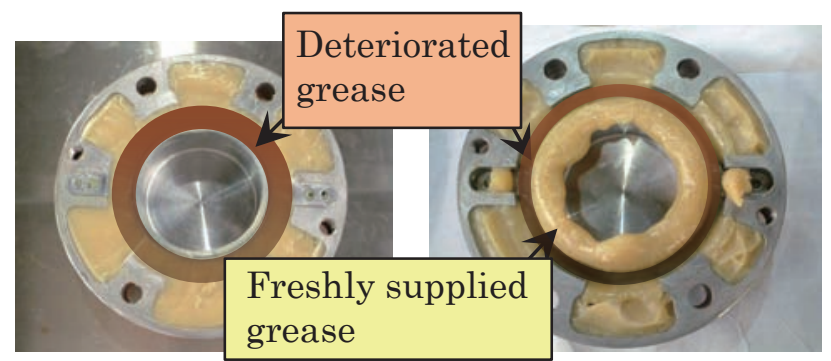

Fig. 4 Deteriorated surface of the grease pocket facing the bearing before (left) and after (right) the interim grease supply

and then after (right) interim greasing. The yellow-colored grease which was at the back is squeezed out through the annular clearance. Since there are two feeding lines in the conventional greasing method with openings facing the bearings, the traction shaft rotates at a low speed to ensure equal distribution of grease during the operation. In the new system however the grease is fed through an aggregated channel on the shaft side into the annular clearance between the grease pocket inner wall and the moving device inner wall, removing the need for low speed rotation since grease is supplied directly to the inner ring. The new system therefore overcomes the drawbacks in the conventional system by improving initial lubrication and stability of grease supply. Better control of the grease supply in turn ensures correct supply of grease to the bearings throughout their service life and maintains stable lubrication conditions.

\subsection{Discussion for practical design}

As described above, the new greasing system involves the addition of a new component. As a result the objective set for improving the design of this new component was to make it lighter and facilitate its cleaning and reassembly during disassembly inspections as much as possible. Figure 5 is the proposed end cap and new component design.

The new mechanism can be adapted for both sides of the bearing. The set functions of the mechanism were modeled in order to verify this application. Although this would
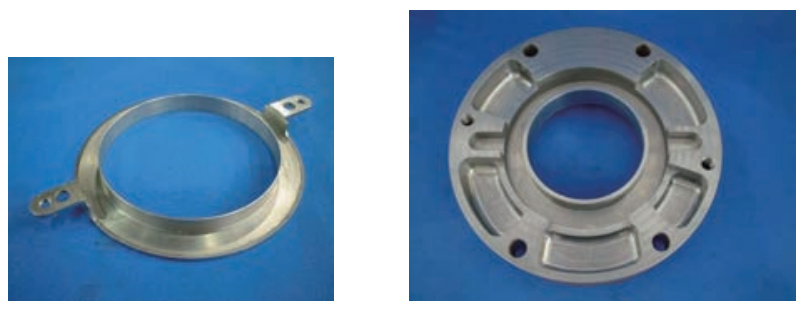

Fig. 5 Final Structure of the mobile component (left) and the end cap (right)

benefit lubrication, it complicates assembly, and so this time, the proposal is for application of the mechanism to the induction traction motor to a side of the bearing only.

There were concerns that the grease may harden in the time before the interim greasing operation. Verifications were therefore also made to check grease penetration (grease hardness) by checking a sample which was subjected to $600,000 \mathrm{~km}$ running in a conventional vehicle with a fresh grease sample, and no problems were found in the greasing operation when the grease sample of the same penetration was packed into the lower component.

\subsection{Movement of the grease supply applied to the motor}

The next step was to verify movement of the grease after supply to the bearings using the new mechanism. The new system is constrained by the very small space in the end cap. By definition the set volume of grease is therefore limited. As such the force achieved to flush the old grease out may not be enough and insufficient grease is supplied. This in turn means that lubrication would not be improved.

In order to check the movement of the grease and the extent to which grease is actually changed in the bearings, the new system was compared with the conventional system using tracers [4] on the main traction of a Shinkansen bullet train. The inside bearing grease pockets were not modified. Tracers were mixed into the grease in order to indicate movement of their base oil. The traction motor was then rotated for several hours.

After rotation at a speed of $4200 \mathrm{~min}^{-1}$, interim greasing was performed before setting the traction motor again into rotation. Tracer concentration around the bearings was then checked. Figure 6 illustrates the grease's behavior around the roller bearings, represented by the tracer distribution after rotation. The vertical axis shows tracer concentration where the original concentration is one. The fresh grease supply is shown to have moved through the bearings and reached the opposite side of the feed opening in both conditions. However, on comparison more movement was achieved with the new mechanism than with the conventional method.

Results demonstrated that not only did the grease not remain in the end-cap grease pocket but also penetrated through to the opposite side of the bearings. This indicates that even with application of the new mechanism to one side of the bearing, it should be able to extend the lubrication lifetime. 


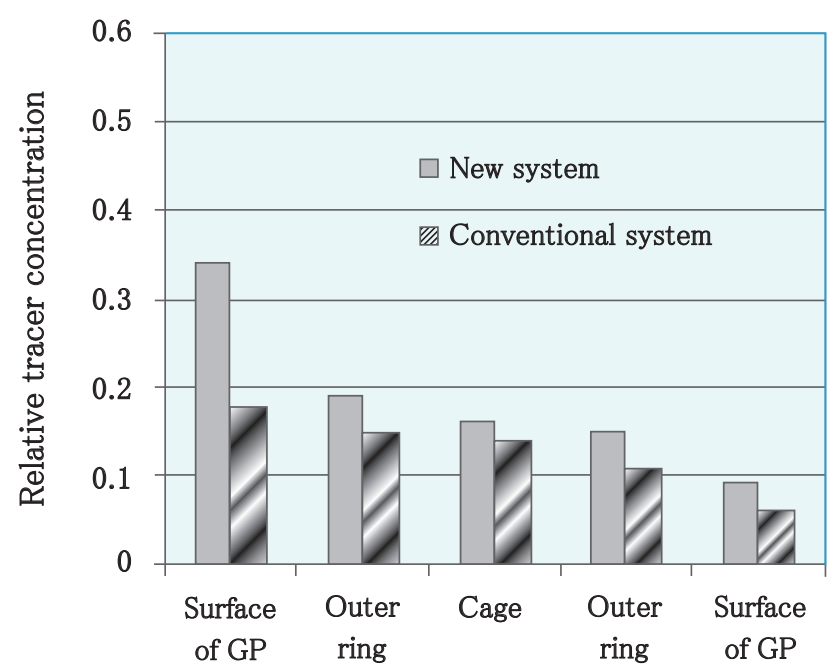

Fig. 6 Grease behavior around the roller bearing represented by tracer distribution after rotation (original concentration is one)

\section{A study on the timing of grease supply}

\subsection{The effects on grease-life extension of mixing new and deteriorated grease}

Another important issue is the influence of timing of greasing on grease-life extension. Although it is expected that interim greasing will extend the duration of greaselife and improve lubrication[5], there is little knowledge about how to make greasing methods even more effective. This paper therefore also focused on gaining insight into some fundamental questions such as "timing" and "appropriate additional volumes of grease" . Tests were carried out to measure the impact of these two elements on grease life with an induction motor and mixing fresh and deteriorated grease.

Samples of grease were taken from over 10 Shinkansen traction motors, having run either approximately $400,000 \mathrm{~km}$ or $800,000 \mathrm{~km}$ and showing different states of deterioration (subsequently labeled D40 and D80). The lifetimes of these samples were compared with that of samples which had been mixed with varying ratios of new grease.

Tests were performed on an ASTM grease-life test machine, according to "the standard test method for functional life of the ball bearing greases" (formerly ASTM D174186). This method is intended as a screening test using two ball bearings, under a temperature controlled by a heater at $125{ }^{\circ} \mathrm{C}$ in the outer rings, repeating a cycle of 20 -hours running and 4-hours intermission, until the earliest positive evidence shown in Table 1 is detected of bearing distress which is still widely used to evaluate the functional lifetime of the grease even after the standard was abolished. The motor and heater are shut off during the intermission. Under normal circumstances approximately 6.0 $\mathrm{g}$ of grease is applied to the bearings, however, to shorten the testing periods and augment the number of results, this volume was reduced to $2 \mathrm{~g}$ to accelerate deterioration for the test. The test conditions are as shown in the Table 2 and results are shown in Fig. 7.

Firstly, the remaining lifetime of the D40 grease was
Table 2 Testing conditions for the accelerated deterioration test using small bearings

\begin{tabular}{|c|c|}
\hline Items & Test conditions \\
\hline $\begin{array}{c}\text { Test bearings } \\
\text { A mount of grease } \\
\text { packed }\end{array}$ & $\begin{array}{l}6306 \text { D eep groove ball bearing } \\
2.0 \mathrm{~g}\end{array}$ \\
\hline Temperature & $125^{\circ} \mathrm{C}$ (O uter rings) \\
\hline Rotation Speed & $3500 \mathrm{~min}^{-1}$ \\
\hline Load & $\begin{array}{l}\text { Radial : 111.1N (11.34 kgf) } \\
\text { Axial : } 177.8 \mathrm{~N} \text { (18.14 kgf) }\end{array}$ \\
\hline Running Conditions & $\begin{array}{l}\text { Repeated cycles of } 20 \mathrm{~h} \text { running } \\
\text { and } 4 \mathrm{~h} \text { intermission }\end{array}$ \\
\hline $\begin{array}{c}\text { B earing failure } \\
\text { criteria } \\
\text { (ASTM D 1741-86) }\end{array}$ & $\begin{array}{l}\text { One of the following: } \\
\text { Stalling of the motor during } \\
\text { operation } \\
\text { Stalling of the motor when } \\
\text { attempting to restart after } \\
\text { shutdown } \\
\text { Temperature rise of } 10^{\circ} \mathrm{C} \text { above } \\
\text { the control temperature, or } \\
\text { Distinct increase in the noise } \\
\text { level which persists for } 10 \\
\text { minutes, either intermittently or } \\
\text { continuously }\end{array}$ \\
\hline
\end{tabular}

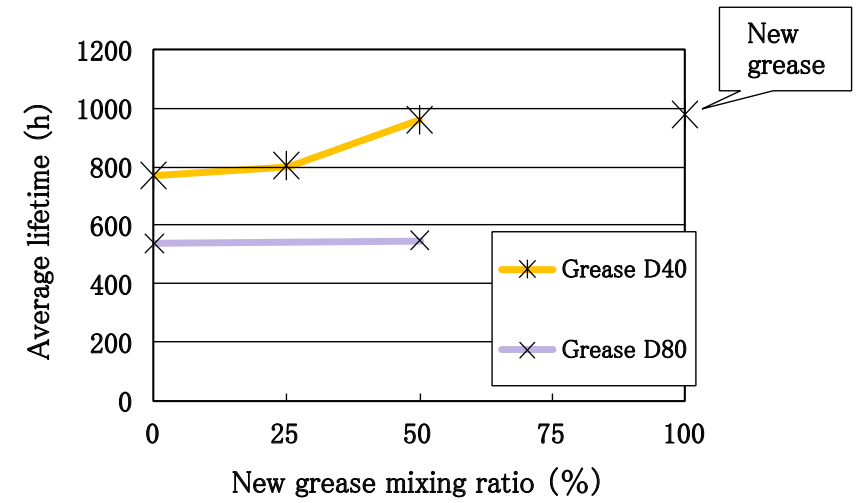

Fig. 7 Lifetime extension by mixing new and deteriorated grease

found to be prolonged when mixed with new grease at ratios of $25 \mathrm{wt} \%$ and $50 \mathrm{wt} \%$.In the case of D80 grease however no grease life extension was observed after mixing with fresh grease. These results suggest that beyond a certain level of deterioration, addition of fresh grease has no impact on grease life. Consequently, the interim greasing operation would need to be implemented when deterioration is still at fairly low.

However, there is no technique available to accurately predict extension to service life based on grease life with- 
out interim supply. Given that effect of interim greasing depends on type of grease, the ratio of additional grease volume to original volume, type and size of bearing and time of greasing, actual railway data on this matter would have to be collected in order to gain more accurate insight into and predict its benefits.

\subsection{The effects of grease-life extension through addi- tion of new grease under operational conditions}

Previous tests used a kneaded and prepared mixture of deteriorated and new grease. The following tests aimed to reproduce real operational conditions. New grease was directly added to the deteriorated grease in the bearing without disassembly using the former standard procedure ASTM D1741 mentioned above.

\subsubsection{Test conditions}

The total amount of grease in each test was identical because in practice the space around the bearings to be filled with grease is also limited. The total amount of grease was fixed at 2 grams. Comparisons were made between cases where $80 \%$ of this was applied as the initial amount and $20 \%$ as the additional amount and cases where the whole volume was applied from the start.

The grease life for when the entire volume was applied from the start (hereafter standard lifetime) was obtained and a set of results was produced for when $20 \%$ of the grease volume was added at different stages of the standard lifetime, namely: $12.5 \%, 25 \%, 50 \%$ and $75 \%$ of the standard lifetime. For these experiments, the average lifetime for each set of three results was obtained.

\subsubsection{Results}

Figure 8 shows the average lifetimes. Their comparison reveals that the greatest extension to grease life was achieved with interim greasing at $25 \%$ of the standard lifetime.

There was almost no effect of prolongation of grease life with additional greasing at $12.5 \%$ of the standard lifetime. In the case of greasing at $75 \%$ of the grease lifetime, the bearing failed before the necessary time had elapsed, showing that the lifetime of $1.6 \mathrm{~g}$ of grease was shorter than the time to scheduled greasing.

These results show that when planning periodicity of vehicle inspection, interim greasing would be most effective during a "Critical Parts Inspection" (every four years or every $600,000 \mathrm{~km}$ ) for a total running distance of 1.8 million $\mathrm{km}$.

\section{Validation trial on test bench with full scale bear- ings}

\subsection{Test specimen and grease}

The modified greasing mechanism prototype was designed in line with available space around the bearings based on an actual traction motor with an unmodified full size end cap. The grease employed in the trial was the same as the lithium complex grease actually used for this type of vehicle motor (Table 1 ). The grease pockets on both sides of the bearings were filled to capacity (full-pack) while the volume of grease applied to the bearings filled $30 \%$ of the inner space around the bearings.

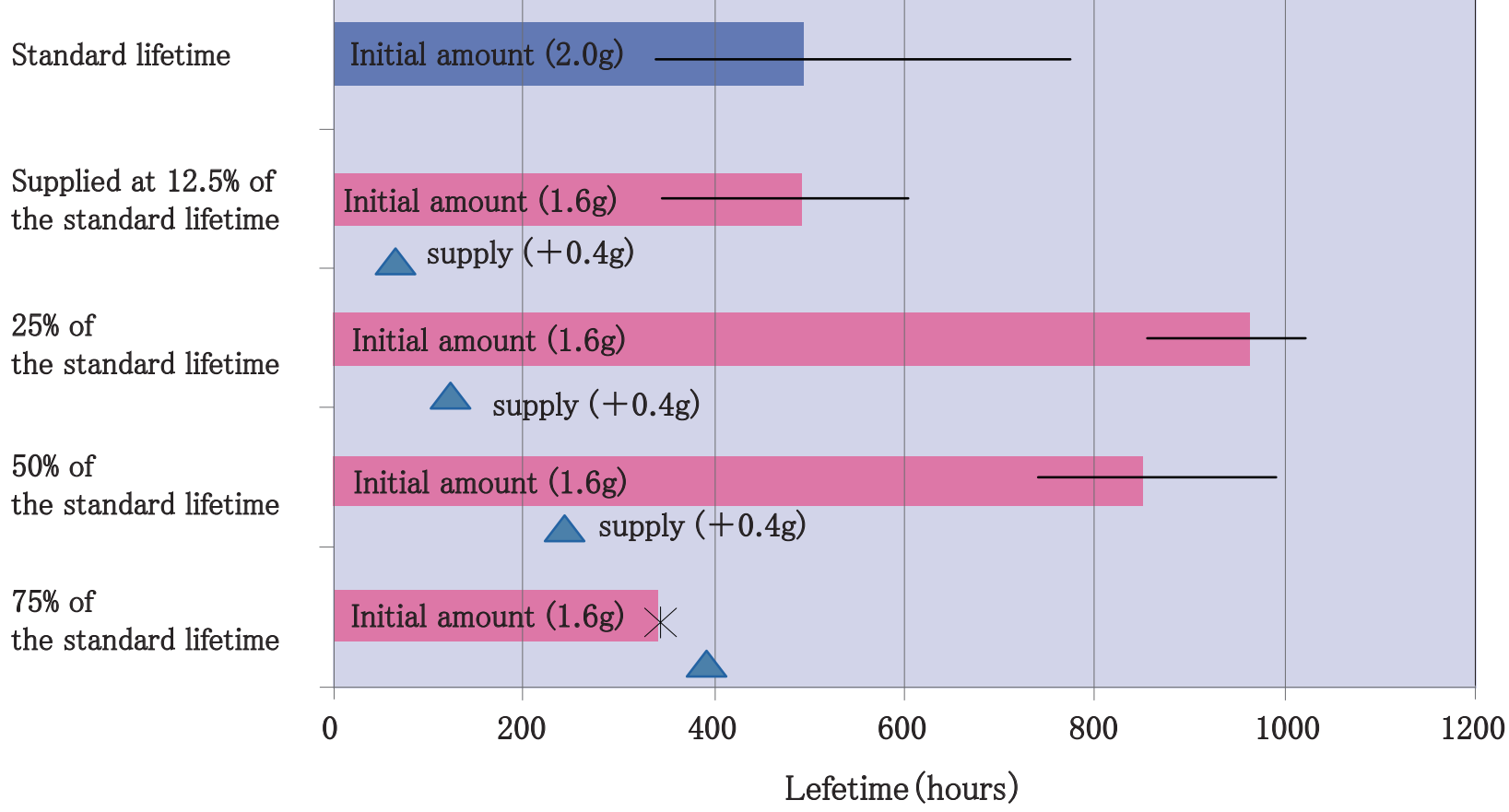

Fig. 8 Effect of changing the timing of interim greasing during the operational lifetime 


\subsection{Test method}

In order to validate the effect of the new interim greasing system on lubrication service life, bearing rotation tests were performed with the model mentioned above in conditions reproducing a running distance of 1.8 million $\mathrm{km}$. The test conditions are shown in Table 3 . The rotational speed was fixed 10 percent above the maximum speed $(130 \mathrm{~km} /$ h) in relation to the conventional vehicle characteristics, in a cycle of 20-hours running and 4-hours intermission. The temperature of the bearings was estimated from the results of actual running tests at speeds of $130 \mathrm{~km} / \mathrm{h}$ and annual mean temperature. The interim greasing operation was performed after $600,000 \mathrm{~km}$ on the basis of the above mentioned findings.

The presence of precursory signs listed in Table 3 was used as the standard during the test to determine the end of the service life. However, no precursory signs were observed before the lapse of the equivalent to 1.8 million $\mathrm{km}$.

Table 3 Testing conditions for the bench test using full scale bearings

\begin{tabular}{|c|c|}
\hline Items & Test conditions \\
\hline Test bearings & $\begin{array}{l}6311 \text { Deep groove ball bearing } \\
\text { NU } 214 \text { Roller bearing }\end{array}$ \\
\hline Temperature & $\begin{array}{l}88^{\circ} \mathrm{C}(6311) \\
98^{\circ} \mathrm{C}(\mathrm{NU} 214)\end{array}$ \\
\hline Rotation Speed & $6044 \mathrm{~min}^{-1}$ \\
\hline Load & Radial : $800 \mathrm{~N}$ (82.6kgf) \\
\hline Running Conditions & $\begin{array}{l}\text { R epeated cycles of } 20 \mathrm{~h} \text { running } \\
\text { and } 4 \mathrm{~h} \text { intermission }\end{array}$ \\
\hline $\begin{array}{c}\text { Bearing failure } \\
\text { criteria } \\
\text { (ASTM D 1741-86) }\end{array}$ & $\begin{array}{l}\text { One of the following: } \\
\text { Stalling of the motor during } \\
\text { operation } \\
\text { Stalling of the motor when } \\
\text { attempting to restart after } \\
\text { shutdown } \\
\text { Temperature rise of } 10^{\circ} \mathrm{C} \text { above } \\
\text { the control temperature, or } \\
\text { Distinct increase in the noise } \\
\text { level which persists for } 10 \\
\text { minutes, either intermittently or } \\
\text { continuously }\end{array}$ \\
\hline
\end{tabular}

\subsection{Transition rate to oxidation deterioration in the roller bearing}

In order to gain further insight into grease deterioration rate, grease samples were taken from the roller bearing after each $300,000 \mathrm{~km}$ of equivalent distance run by

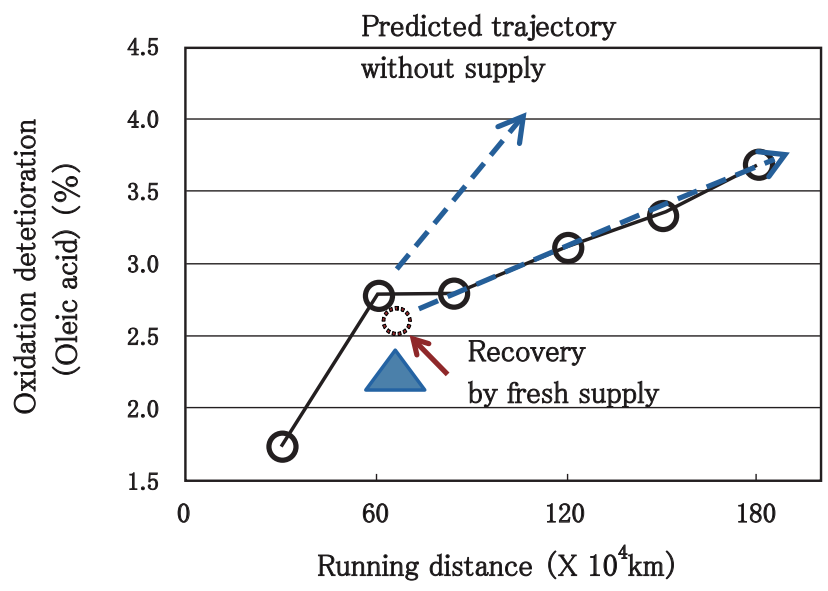

Fig. 9 Change in oxidation deterioration rate of the grease in the roller bearings during confirmation bench tests

Table 4 The transition in the oxidation deterioration rate at a running duration

\begin{tabular}{|c|c|c|c|c|c|c|}
\hline $\begin{array}{c}\text { Running } \\
\text { distance } \\
\text { (in } 1,000 \mathrm{~km} \text { ) }\end{array}$ & 300 & 600 & 842 & 1200 & 1500 & 1800 \\
\hline $\begin{array}{c}\text { Oxidation } \\
\text { deterioration } \\
(\%)\end{array}$ & 1.74 & 2.78 & 2.81 & 3.12 & 3.35 & 3.70 \\
\hline
\end{tabular}

interrupting the experiment. Fresh grease was applied immediately after the sample was taken at $600,000 \mathrm{~km}$. No sample was taken immediately after greasing. Given that the same set of bearings was being rotated continuously in the test, in order to minimize the impact of sampling on the running, grease samples were taken from a different and only one of the 16 rows of bearings in the cage each time. Sampling reduced the quantity of grease in the bearing, but no extra grease was added to compensate this. The progress of oxidation deterioration is shown in Fig. 9 and Table4. It is apparent that the grease in the bearing gradually oxidized. As oxidation increases, so does the value for oleic acid which is the criterion for oxidation deterioration.

\subsection{Discussion}

No grease samples were taken immediately after regreasing, however, given the subsequent progress of deterioration it is possible to posit that the oxidation value fell to the point indicated in the graph corresponding to that time. It could be concluded that this drop - i.e. deterioration being inhibited - leads the extension to lubrication.

Furthermore, the gradient of the line representing the ageing of grease demonstrates that interim greasing slows the deterioration process, when compared to the gradient of the slope illustrating deterioration from the start of the experiment up to the time of interim greasing. Grease deterioration in the first stage prior to interim supply is faster given that only half the volume of grease contained in the annular GP is being used. After interim greasing, the 
amount of grease from the grease pocket increases, slowing deterioration.

\section{Conclusion}

The authors developed a new technique for interim greasing and confirmed its applicability for replenishing grease in the bearings. This method allows the following without disassembly:

(1) Flushing out and replacing deteriorated grease with fresh grease, (2) No need to leave unfilled space adjacent to the bearings, (3) Control of refill grease volume, (4) Increase the volume of refilling grease without providing empty space.

According to the comparative tests to determine optimum timing for interim greasing, lubrication life time would appear to be maximized when the greasing operation is performed a quarter of the way through the standard lubrication lifetime.

Finally, full scale bench tests confirmed that the extension to lubrication lifetime obtained through the new greasing mechanism and optimal greasing periodicity was applicable to the conventional vehicle required running distance of 1.8 million $\mathrm{km}$ before inspection by disassembly.

\section{Acknowledgment}

This research was conducted by RTRI in association with the TOSHIBA Corporation.

\section{References}

[1] Hibino, S., Hosoya, T., Sone, Y., Nakamura, K. and Suzuki, M., "Shape of Grease Pocket to Facilitate Base Oil Migration,” RTRI Report, Vol. 18, No. 10, pp. 21-24, 2004 (in Japanese).

[2] Japanese Society of Tribologists, Tribology Handbook ( $1^{\text {st }}$ Edition). Yokendo Ltd., Tokyo, Japan, p. 851, 2001 (in Japanese).

[3] S. Hibino, K. Nakamura, T. Hosoya, K. Matsuoka, T. Nagayama, T. Sunohara and M. Kitamura, "A Proposal of New Interim Grease Supply Method for Induction Traction Motors," presented at the World Tribol. Congress., Kyoto, Japan, September 6-11, 2009, Proceedings of World Tribology Congress, Kyoto 2009, 1 (2009) 813.

[4] Hibino, S., Hosoya, T., Sone, Y., Nakamura, K. and Suzuki, M., "Lubricating Motion of Grease in the Bearing of Induction Motor," presented at the Int. Tribol. Conf., Nagasaki, Japan, October 29-November 2, 2000, Proc. Int. Tribol. Conf., Nagasaki 2000, 1, 2001, 1,401-1, 405.

[5] Research Committee on Lubricating Greases of Japanese Society of Tribologists, "Report of Joint Research on the Lubrication Life by Mixture of Deteriorated Grease and New Grease," Journal of JAST, Vol. 47, No. 3 pp. 184-189, 2002 (in Japanese). 